
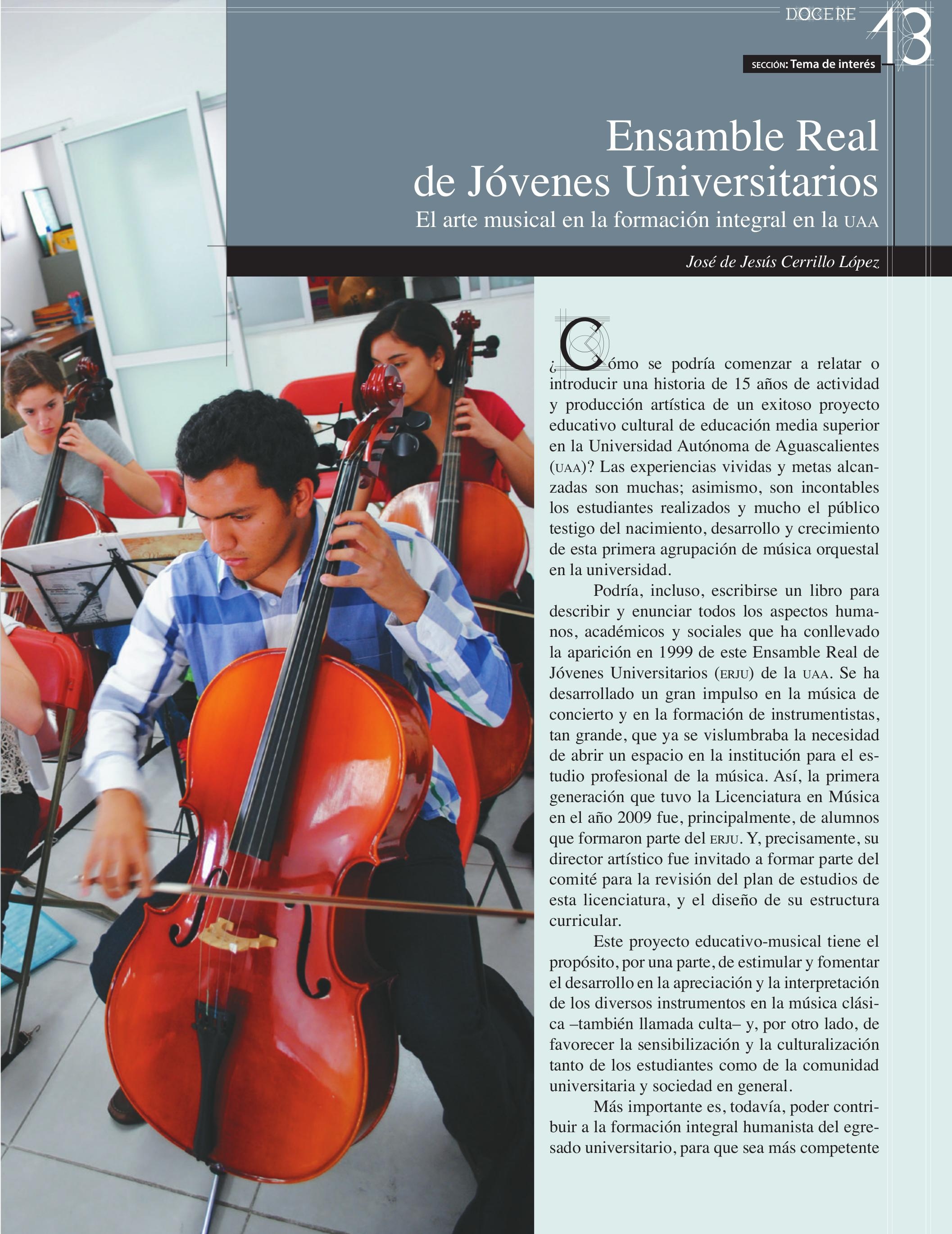

José de Jesús Cerrillo López 
en su vida profesional, laboral y social, y aporte a la generación de una sociedad del más alto nivel, con una cultura de mejor calidad.

Con el estudio constante de un instrumento orquestal, se genera en el estudiante una conciencia de disciplina que le permite lograr un resultado, fruto de su devoción y perseverancia, provocándole un sentimiento de satisfacción al alcanzar su meta. Lo anterior también llega a verse reflejado en todas sus demás actividades académicas y personales. El estudiante se descubre, ve sus capacidades y comienza a fortalecer y a desarrollar una personalidad competente, con la cual podrá mejorar su calidad de vida.

\section{La música y el cerebro}

¿Qué tanto influye la escucha o práctica de un instrumento musical en nuestro cerebro? Definitivamente la música es determinante en las funciones cognitivas, sensoriales, mentales y también en efectos de paz y bienestar. El hemisferio derecho del cerebro es el sensitivo-artístico y se equilibra armoniosamente con el hemisferio izquierdo, el cual es el analítico-científico, y dependen uno del otro, realizando sus respectivas tareas. El cerebro es perfecto.

Jazmín Sambrano explica, en su libro El placer de aprender a aprender, cómo cierta música contribuye a lograr el estado de conciencia necesario para el total aprovechamiento de nuestras capacidades (2009: 15). Menciona que para el superaprendizaje (potenciación integral en la capacidad de aprender), la música contribuye a facilitar la relajación y la producción de ondas alfa en la actividad cerebral, lo cual favorece un aprendizaje más eficaz, sin tensión y con la mente alerta (estas ondas producen, aparte del estado de relajación, una óptima integración de cuerpo y mente) (2009: 24).

De igual manera, el educador musical estadounidense, Michael Mark (2002: 280), menciona que:

A través de la educación musical los estudiantes desarrollan su inteligencia musical. Definiendo cognición humana, la inteligencia musical es reconocida como una de nuestras inteligencias autónomas. El hecho de que los humanos pueden pensar en sonidos y ritmos y organizarlos en patrones y formas para dar representación a una vida sensitiva es una capacidad única.

También, a los estudiantes en música se les facilita hablar y entender idiomas diferentes al español. La comunicación oral y escrita dentro del ERJU puede ser en inglés, en francés, en italiano y hasta en alemán, y los integrantes se activan y disfrutan realizando todo tipo de frases multilingües porque se les facilita, y además forma parte de la propia actividad y formación.

En el ERJu, las competencias ${ }^{1}$ están implícitas desde el inicio; el estudiante es el sensor y motor de esta actividad formativa. El arte es humano, la música se revela al propio ser, los jóvenes se extrovierten y explotan sus virtudes... se hermanan en una actividad grupal y armoniosa por la consecución de una expresión artística; ésta se difunde y se comparte en la presentación de los conciertos. El ser humano se muestra a plenitud en su naturaleza propia... es la manifestación de su espíritu elevado.

1 Legendre (1993: 223, citado en Méndez, 2007: 3) define la competencia en el campo de la didáctica y de la pedagogía como una habilidad adquirida gracias a la asimilación de conocimientos pertinentes y a la experiencia; dicha habilidad permite detectar y resolver problemas específicos. 


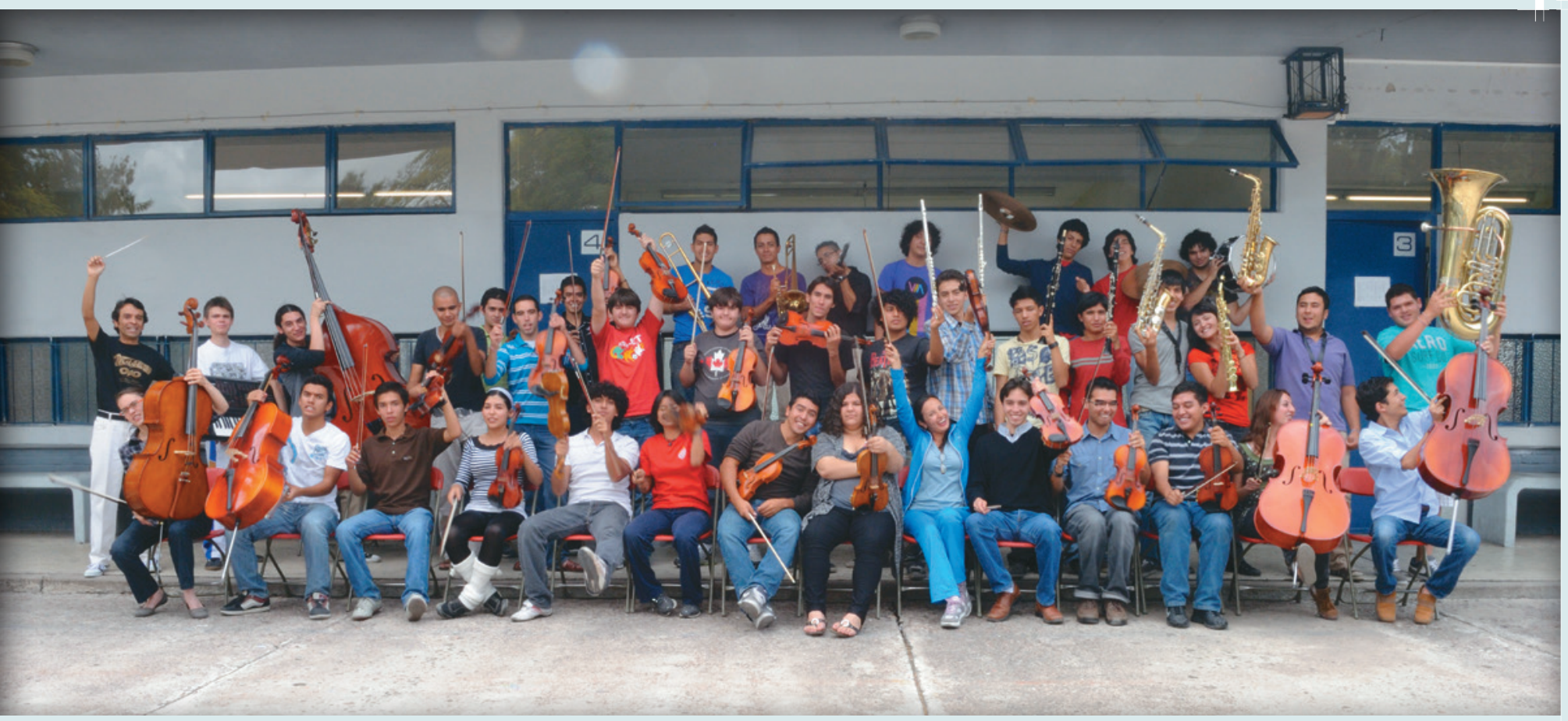

En los Lineamientos de Actividades Artísticas y Culturales de la SEP se señala que: "el propósito fundamental de las Actividades Artísticas y Culturales en el contexto del Marco Normativo del Bachillerato General es el de contribuir al desarrollo de las competencias genéricas transversales [...]" (2010: 8).

Mavilo Calero, por su parte, señala que ante las demandas individuales, sociales e institucionales surgen las competencias saber (manejo conceptual), saber hacer (manejo procedimental) y saber ser (manejo actitudinal), mismas que llevarán a una adecuada educación integral; y se añade también la de convivir (aprender juntos), recalcando al respecto que: "La actividad grupal es siempre mucho más rica y provechosa que la actividad individual" (2009: 37 y 100).

\section{La formación humanista en el ERJU}

El ERJU ha fortalecido la academia universitaria por revelarse como un potencial desarrollador de la formación humanista dentro del estudiantado, la cual es un eje central para el desarrollo integral del universitario.

$\mathrm{Al}$ respecto, Michael Mark expresa lo siguiente:

La música hace una diferencia en la vida de las personas; exalta el espíritu humano y mejora la calidad de la vida. La música es una manera básica de saber y saber hacer debido a su misma naturaleza y su relación con la condición humana incluyendo mente, cuerpo y sentimiento (2002: 267).

Por su parte, el precursor y padre de la formación humanista en la UAA, Amador Gutiérrez Gallo, señala que: “con la formación humanista como elemento transversal a la formación técnico-científico-profesional, no se pretende formar profesionales de las humanidades, sino profesionistas que ejerzan humanísticamente su profesión" (2003: 20). 
La misión de la UAA es lograr una educación orientada al desarrollo integral de la personalidad mediante la investigación científica y humanística buscando que los universitarios se distingan por una sólida cultura general y que desarrollen la sensibilidad hacia diversas manifestaciones artísticas y culturales (2008: 2).

El actual rector, Mario Andrade Cervantes, asiduo asistente a los conciertos del ERJU, ha manifestado continuamente su apoyo y admiración a esta agrupación: "El Ensamble Real de Jóvenes Universitarios es muestra del talento destacado que existe en los aguascalentenses, y quienes en un futuro próximo serán los que coordinen el desarrollo artístico musical de México" (UAA, s/f).

En décadas pasadas, con la falta que existía en programas de música clásica dentro de la institución y la poca atracción y acercamiento de los jóvenes hacia la música orquestal, se observó la necesidad de integrar estos géneros a la formación académica-humanista de los estudiantes. Desde la aparición del ERJU en el escenario universitario hace 15 años, sus integrantes han encontrado esa fusión y complemento en su formación integral. Centenares de alumnos, tanto del bachillerato como de la mayoría de las licenciaturas de la UAA, han pasado por las filas de este Ensamble Real desarrollándose conjuntamente en el arte y en la ciencia, en lo personal, social, y en lo profesional, descubriendo una manera completa de vivir y formarse.

Por lo anterior, el ERJU ha marcado un antes y un después en la cultura universitaria, ha impactado no sólo en la formación académica de los estudiantes sino que también ha abierto el acercamiento y la sensibilización a la música clásica de concierto a la comunidad universitaria.

\section{Fuentes de consulta}

Calero, M. (2009). Aprendizajes sin límites. Constructivismo. México: Alfaomega.

Cerrillo, J. (2003). Análisis sobre programas de materias artísticas en la UAA. México: UAA-CEM.

Cerrillo, J. (2014). Iniciación al Ensamble Real de Jóvenes Universitarios. Programa de Curso: UAA.

Gutiérrez, A. (2003). La Formación Humanista en la Universidad Autónoma de Aguascalientes. (PDF). Dirección General de Docencia de Pregrado, UAA.

Legendre, R. (1993). Dictionnaire actuel de l'éducation. Montréal, Québec, Guerin.

Mark, M. (2002). Music education. Source readings from ancient Greece to today. New York: Routledge.

Méndez, A. (2007). Terminología pedagógica específica al enfoque por competencias (PDF). Bélgica.

UAA (2008). Ideario de la Universidad Autónoma de Aguascalientes. Recuperado en febrero de 2015 de http://www.uaa.mx/nu/.

Sambrano, J. (2009). El placer de aprender a aprender. Superaprendizaje para todos. México: Alfaomega.

SEP (2010) Lineamientos de Actividades Artísticas y Culturales de la SEP. Bachilleratos (PDF). México: DGB-DCA.

UAA (s/f). Exitoso concierto del Ensamble Real de Jóvenes Universitarios. Boletín No. 798. Recuperado el 2 de diciembre de 2014 de http://bit. ly/1vAvdNm. 